\title{
E-Government and Online Government-Citizen Interaction
}

A Prospective Theoretical and Analytical Framework for Investigating Their Effects on the Organisation of Public Administrations and Service Delivery

Working paper

Ana Waksberg Guerrini (awaksberg@uoc.edu)

Doctoral candidate: Doctor's degree in the Information and Knowledge Society

\author{
Working Paper Series WP08-003 \\ Research group: GADE \\ Coordination: Albert Batlle Rubio \\ Submissed in: July 2008 \\ Accepted in: July 2008 \\ Published in: September 2008
}

\section{$\bullet$ UOC \\ IN3 Internet \\ Institute}

wWw. uoc.edu 
Internet Interdisciplinary Institute (IN3)

http://www.uoc.edu/in3

Parc Mediterrani de la Tecnologia

Av. Canal Olímpic, s/n.

08860 Castelldefels

Barcelona (Spain)

Tel. 936735000

Universitat Oberta de Catalunya (UOC)

http://www.uoc.edu/

Av. Tibidabo, 39-43

08035 Barcelona

Spain

Tel. 932532300

This report, unless otherwise indicated, isubject to a Creative Commons Attribution-Noncommercial-

(c)

SORERIGHIS RESERVED
NoDerivativeWorks 2.5 Spain licence. It may be copied, distributed and broadcast provided that the author and the institution that publishes it (UOC) are cited. Commercial use and derivative works are not permitted. The full licence can be consulted on http://creativecommons.org/licenses/by-nc$\underline{\text { nd/2.5/es/deed.en }}$ 


\section{Table of Contents}

Abstract

1. Introduction 05

2. Literature Review and Some Questions

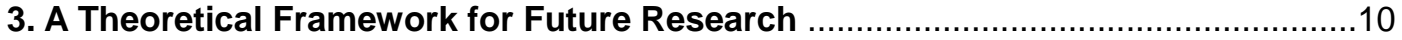

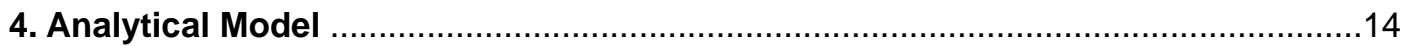

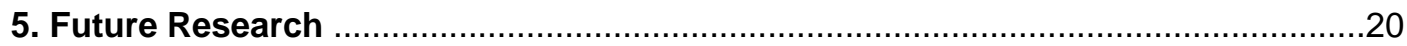

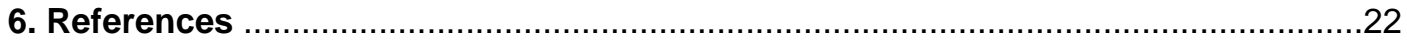




\title{
E-Government and Online Government-Citizen Interaction
}

A Prospective Theoretical and Analytical Framework for Investigating Their Effects on Public Administrations Organisation and Service Delivery

Ana Waksberg Guerrini (awaksberg@uoc.edu)

Doctoral candidate

\begin{abstract}
During the last decade public administrations have placed special effort into developing government portals and offering online services. The aim of this paper is to set up a theoretical and analytical framework to investigate the effects of the new technological-based channels of interaction between governments and citizens on the organisational structure and dynamics of public administrations and ultimately on service delivery. It also points towards possible methodological approaches that might prove useful in future research on the theme.
\end{abstract}

\section{Keywords}

e-government, information government, public administration, network administration, organisational change

\section{Recommended citation:}

WAKSBERG-GUERRINI, A. (2008). E-Government and Online Government-Citizen Interaction: A Prospective Theoretical and Analytical Framework for Investigation Their Effects on the Organisation of Public Administrations and Service Delivery [working paper online]. UOC. (Working Paper Series; WP08003). [Date of visit: $\mathrm{dd} / \mathrm{mm} / \mathrm{yy}$ ]. <http://www.uoc.edu/in3/dt/eng/waksberg.pdf $>$ 


\section{Introduction}

According to network society theorists (Castells 1996, Van Dijk 1999, Wall Smith 2002) social structures and activities in every societal area are increasingly organised around network forms, largely grounded in electronically based information and communication technologies (ICTs). Governments, however, are apparently lagging behind in up-taking this new logic. Contemporary public administrations have become increasingly more complex, having to coordinate actions with emerging actors in the public sphere, and manage and process increasing amounts of information; thus the silo like, inward-looking culture, slow decision-making and knowledge diffusion (Schellong 2007) of the old bureaucratic model seem to be ill-suited to improve flows of information and cooperation, levels of legitimacy and trust as perceived by citizens, and ultimately efficiency and efficacy.

In this scenario the modern ICTs and "e-government" have, since the middle of the 1990s, begun to be seen as an ideal vehicle to resolve some of the problems of contemporary public administrations face. The usual argument is that the intensive use of technology could transform the operating rules of the public administration to increase its efficiency, simplify administrative procedures (Fountain 2005), expand the processes of citizen participation (Hague and Loader 1999) and make the activity of governments more transparent and accountable (Bhatnagar 2003). In the context of these high expectations there is a clear need to explore the extent to which public administrations are undergoing a process of transformation linked to the systematic incorporation of ICTs in their basic activities. It is particularly interesting to verify whether governments are becoming more flexible, opaque and permeable to citizens' preferences, and whether there is a transition towards a new form of network organisation at the core of the public administrations that might be conceptualised as a virtual state (Fountain 2001) or, as a network administration (Castells and Ollé 2004; Aibar and Urgell 2004).

The literature on e-government have traditionally focused on the transactional aspect of egovernment, analysing how the offer of online services could develop from informational to transactional; studies have also been carried out on the implications of e-government on the backoffice of public administrations, based on costs and efficiency gains. More recently, the topic of citizen-centricity in e-government has come into prominence, particularly with the rise of the concept of Web 2.0. 
What is missing in the research on ICTs in the public sector are consistent empirical studies at the intersection of these perspectives - the front office, the back office, and the increasingly importance given to citizen-centricity - that would tackle, for instance, the effects of the i) information about citizens' online behaviour while using e-government services, ii) their generation of online content, and of iii) electronic citizen-government feedback mechanisms, on the organisation of public administrations (back office) and ultimately on service delivery (front office).

In this paper I put forward a theoretical and analytical framework that intends to aid the development of future empirical research on the above subjects. It is organised as follows: in the first section, it offers a brief literature review about e-government, followed by a couple of questions arising from it. It suggests three lines of research that by taken together might benefit a research about the effects of the new interaction channels between government and citizens on public administrations: the literature on information government, ICTs and organisational change, and network administration. In the second section of this paper, I attempt to build an analytical model for future research on this area, and, finally, point towards methodological approaches that might be used in future empirical work.

\section{Literature Review and Some Questions}

\subsection{A Brief Account of e-Government Research}

The use of ICTs in government structures is not new, but the concept of e-government became widely used in the 1990s when it began to be seen as a policy strategy to improve service delivery and to cut costs, also aiming at simplifying administrative procedures (Fountain 2005), increase citizen participation (Hague and Loader 1999) and transparency and accountability of government activities (Bhatnagar 2003). The following synthesis of the different views and definitions of egovernment draws from the work of Mayer-Schönberger and Lazer (2007).

E-government was first depicted as the use of ICTS in the offer of online services; within this transaction-oriented view, the attention was given to the swift, and inevitable, evolution of egovernment through defined stages, ranging from the information stage - the web presence of public agencies -to the transaction stage, where public services would be offered online $24 \times 7$ 
(UNPAN). This demand driven and technology fuelled process, with the purpose of facilitating the life of citizens, would in turn supposedly lead to a transformation of the public sector. Studies within this perspective have also focused on issues such as the usability, security, privacy, equity, etc, of government portals.

Contrasting with this view, a much broader definition has been suggested (Dawes 2004), defined as the extensive use of ICTs in all government functions to support government operations, engage citizens, and provide services. The main purpose of e-government would be making the public sector's activity more efficient and save public resources, achieving better governance. While this view encompasses online public services, the focus here shifts to the use of ICTs in the "inner workings" of government (Mayer-Schönberger and Lazer 2007). The literature on this perspective of e-government have analysed the organisational and structural changes of the public sector with the intensive use of ICTs, its efficiency and performance (Osborne and Gaebler 1992), and the challenge of institutional change and technology enactment in public organisations (Fountain 2001), among others.

Finally, others characterise e-government as explicitly incorporating democratic processes, although this view is generally placed under the label of "e-governance". More recently, greater attention has been given to citizen-centricity in e-government projects. The literature on e-business and ecommerce have long emphasised "customer-centricity" in the process of finding out customers' needs. Successful cases of e-commerce and e-business, such as Amazon and Zara, have clearly based their strategies on demand-driven and customer centric projects, with a constant search for understanding and fulfilling customers' desires to generate their loyalty (Blakemore 2006). In the case of e-government's practise and literature, we notice a discourse about user-centricity particularly with the rise of the concept of Web 2.0; however, citizen-centricity in the strict business sense is unlikely to happen in the public sphere as for governments the search for profit cannot be the natural incentive for a user-centric approach, as the model that guides management in the public domain has different purposes and conditions (Steward and Walsh, 1992). 


\subsection{Feedback Mechanisms, Citizens' Online Behaviour, and Flows of Information: Some Questions}

Based on the literature review and the analysis of e-government practices we ask whether new technology-based windows of interaction between governments and citizens particularly related to "e-services" play a significant role in restructuring public administrations and ultimately sparking transformations in the delivery of public services. In this research, "technology-based windows of interaction" are the new forms of information and communication between governments and citizens made possible through the internet, but also the telephone. A result of their use is a vast amount of aggregated information about citizens' demands, complaints, and suggestions, on one hand, and patterns of use of online and telephone services, on the other.

Based on observation and on empirical evidence (Aibar, Urgell and Welp 20), we hold the hypothesis that the new windows of interaction affect the organisational dynamics of public administrations, leading to some improvement in the delivery and quality of public services; we believe that these new interaction channels and the changes in the organisational dynamics do not significantly affect the institutional organisational structure of public administrations. Although radical transformations in the formal structure of the organisations are not expected findings, and high levels of hierarchy and compartmentalisation are still present in most governments, we have some empirical evidence that transformations are occurring in the informal organisational dynamics of administrations. We believe it is also of extremely relevance for future work to investigate the format this organisational dynamics may be taking, with relation to these new interaction possibilities.

Specifically, we understand that analysis should be carried out on if, and how, the new channels of communication and interaction between governments and citizens regarding public services that have emerged with the intensive use of ICTs (email, online forms, forums, chats, call centres, etc) affect the organisational structure and dynamics of the administrations and how this in turn is reflected into the delivery of public services. Particularly, in order to understand this dynamics, we believe it should focus on the destiny of the vast amount of aggregate information, produced by these interactions, about citizens' preferences and behaviour regarding public services, and how and if they affect the administrations. The citizen may in that way be becoming, besides the "final user", the engine of the transformation process, through his or her patterns of online service use and feedbacks (Dunleavy and Margetts 2000). 
If we take a broad idea of Web 2.0 in the public administration context as the co-production and design of services, it becomes extremely relevant to answer if the above mentioned class of information is being used by governments, whether it is pressuring it to be more open and less hierarchical, and whether it is shaping and transforming the delivery and quality of public services, through simultaneously reorganising the administration and re-constructing the user.

We put forward in this prospective paper that future research on these themes might benefit from the combination of literature on information government, the theories about ICTs and organisational change, and the research body on network society and more specifically on network administration, to analyse information flows within administrations and between governments and citizens in order to understand the nature of transformations.

\section{A Theoretical Framework for Future Research}

ICT implementation in governments does not necessarily represent an immediate vast reduction in costs running the government, as this requires investment in major projects, which often experience substantial cost overruns (Borins 2007); also, studies in the private sector show that ICTs not necessarily increase productivity of office work (O'Callagham 2004). But at the organisational level, the picture might look different, as research demonstrate that the intensive use of ICTs is positively linked to firm performance and results; case studies show that some organisations have been able to derive benefits through IT (e.g. Wal-Mart, Dell Computers, Charles Schawab) (O'Callagham 2004) in terms of flexibility, performance, responsiveness, intelligence, and accountability.

There are obviously contextual differences that shapes the way ICTs are managed and embedded in the public and the private sector (institutional, type of accountability, provision of services for all versus segmentation, etc.) but we find essential to question if similar transformations are taking place in public administrations and their effects, and this paper is a starting point of this investigation. 


\subsection{Information Government}

The notion of "information government" is a complementary perspective to the concept of egovernment and offers a conceptual lens that further helps to understand the changing nature of government and its relationship with the society. By analysing the information flows within government and between government and citizens, we can examine "where, when, and why they change and what the interaction is between these changes and the public-sector activities" (MayerSchönberger and Lazer 2007). This view is particularly useful to the type of research we propose, and will help us to analyse the flows of the vast amounts of collective information about citizen's preferences and needs, made available through the new channels of interaction between governments and citizens, and their effects on the organisation and dynamics of the public sector. We will explore further the concept and the applications of "information government" in the analytical framework.

\subsection{ICTs and Organisational Change}

Opinions vary as to how ICTs affect organisational structures; it is often understood that ICTs facilitate the emergence of a flatter organisational profile by reducing the number of managers in an organisation. In general, based on empirical research (mostly in the private sector) (O'Callagham 2004), the intensive use of ICTs tend to have the effect of reducing compartmentalisation, the number of departments and secretaries, the hierarchical levels, and improving and horizontalising the internal communication (and decision-making) through the interoperation of data bases and increase of communication channels (Heintze \& Bretschneider 2000, Pinsonneault and Kreamer 1993).

Theory suggests that the intensive use of ICTs can either increase or decrease the number of middle managers, according to the degree of centralisation of decision making power and to the degree of centralisation of control over ICTs, which in turn mirror the economic and political environments surroundings these organisations (Heintze \& Bretschneider 2000, 
Pinsonneault and Kreamer 1993). ICTs are negatively associated with the number of middle managers in organisations that are highly centralised, such as the public sector; consequently, middle managers will likely be only responsible for communication and routine decision making, thus being exposed to the downsizing effects of ICTs. Nevertheless, the extreme rigidity of personnel systems in the public sector and the influence of political forces may greatly reduce these effects.

What seems to be a consensus among researchers is that radical transformations are not being produced in the structure of the public sector by the intensive use of ICTs, neither is the Weberian model being overcome (Fountain 2001). Therefore it is also not expected that the new windows of interaction between governments and citizens would inflict radical changes in public administrations. However, although these transformations in the formal structure of the organisation have not been observed, there is some empirical evidence (Aibar, Urgell and Welp 2007) that transformations are occurring in the informal organisational dynamics of administrations.

\subsection{Network Society and "Network Administration"}

The concept of 'network administration' is closely related to the network structure identified by several authors (Castells 1996, Van Dijk 1999, Wall Smith 2002) in order to characterise the new social morphology of the informational society. Castells $(1996,2001)$ stresses that the phenomenon of the network structure is aided by, although not a simple consequence of, the intensive use of ICTs. He elaborates on how businesses and the economy in the globalised operate nowadays, pointing out to important characteristics of this new organisational form, such as the organisation of activities around projects of limited duration, the flexibility in reconfiguring teams and resources to complete them, the internal decentralisation and cooperation with other companies, all affecting the core operations of the business activity.

By way of analogy, the network public administration could be conceptualised as an organisational form characterised not only by the connection and interoperation between the information systems and the management procedures, but also by a tendency to change the operation of the organisation towards more flexible management, more adaptability to changes and with relationships that are more horizontal than those which predominate in the 
traditional administration. In this type of organisation, the networks between the public and the private sector design and manage public policies, within a contingent and dynamic character, in a political system where the citizen plays a role as a user of public services as well as co-manager of the administrative procedures, through the new forms of participation and interaction (Chadwick 2003; Aibar, Urgell and Welp 2007).

In that sense, it could be associated with the concept of modern governance (Mayntz 2001), which refers to a more distributed and relational manner of governing than that found in the old hierarchical model (Powell, 1990), involving the direct cooperation between public and private actors in the public networks.

And as Chadwick points out: "Network technologies offers the potential to increase political participation and reshape the state into an open, interactive, network form as an alternative to both traditional, hierarchical, bureaucratic organisations and more recent, market-like forms of service delivery based on the "contracting out" of public services activities (...) Proponents of this perspective argue that the widespread use of the Internet means the traditional application of ICTs in public bureaucracies, originally based around inward-facing mainframe computer systems originating in the 1960s, should now be superseded by outward-facing networks in which the division between an organization's internal information processing and its external users effectively melts away".

The objective is not, however, to elaborate on detailed characteristics of an ideal type of network administration and verify its existence in governments, but yet to use this set of aspects as an analytical background when examining the changes in public administrations structure and dynamics and the role of the interaction with citizens in this process.

\section{Analytical Model}

In accordance to the notion of information government, this paper argues that in order to understand the relationship between the emergence of new interactive windows between citizens and governments and the possible reorganisation of the administration, we might gain in depth knowledge about it by looking at the information flows among the actors involved: 
"[O]rganisations are information processing units, and the central means of understanding and analysing organisations is by illuminating the structures and channels organizational actors develop to regularise information collection, storage, use, and flows (Fountain 2007, March and Simon 1958 1993). Are there any changes in the information flows analysed? If there are, are they mirroring the old hierarchical structure or are the information flows moving towards a different organisation dynamics? What are the different constraints and their specific social contexts? With the purpose of understanding these complexities, we suggest three research dimensions: i) the windows of interaction and the treatment of citizens' aggregate information, ii) the levels of information structuring in public organisations and implications of these new interaction channels for public sector organisational structure and dynamics, and finally iii) the effects on service delivery.

It should be noted that we opt for, instead of the traditional analytical model of social or organisational impact of technology - dominant in great part of the literature on e-government - an analytical perspective that emphasises the bi-directional interaction process between technological innovations and the specific social contexts (institutional, organisational and cultural) where these are designed and adopted (Latour 1996). It is considered here that public administrations are not merely passive receivers of technology, but their regulations, processes and own organisational forms play an active and determinant role in the final configuration of the ICTs and are, at the same time transformed in the process of incorporating the technology - a type of phenomenon that has recently been considered by technology-in-practise concepts (Orlikowski 2000), in the general context of organisational theory and by technology enactment (Fountain 2001) in the area of research in e-government.

\section{I) Technology-Based Interaction Windows and Treatment of Aggregate Information about Citizens}

An emergent topic related to citizen-centricity in e-government is Web 2.0. Even though Web 2.0 is a broad concept, it can be roughly defined as the use of new technologies and techniques that enable users to drive greater personalisation and interaction with websites, and ultimately the co-production of content. 
Although not taking the form of Web 2.0 features (wikis, videos, blogs, podcasts, etc), the new tech-based channels of communication and the aggregate information about citizens produced by them form a set of interactions that is characterised in this research as a movement towards a Web 2.0 logic. In other words, the disintermediation process that characterises the web logic (Dunleavy and Margetts 2000) could allow for a co-production and design of services, through using citizens' explicit feedback and the information about their online behaviour, for the restructuring of the administration and public services. We seek to answer if this is happening at any level to later understand whether it is being translated into less hierarchical and more open and flexible governments.

\section{II) Levels of Information Structuring and Effects on Organisational Structure and Dynamics}

In order to analyse organisational change - and which direction it follows - with the advent of the new forms of interaction, we suggest an analysis loosely build around Jane Fountain's Multi-level Integrated Information System (MIIS) model to describe and explain how information is structured at three interrelated levels in public sector organisations (Fountain, 2007). As noted before, e-government does not seem to have produced radical formal organisational changes; however, governments that have embarked on "e-government" have had to rethink information flows, either at the most formal or most informal level, at some degree of complexity, which implies that organisational and interorganisational change will happen to some extent.

The MIIS model divides information flows into three interrelated levels, each following a different internal logic: first, the level where individuals share and make sense of information in small groups though ongoing social relations within and across organisations; at the organisational and inter-organisational level, actors design and use processes and systems to codify and structure information in order to routinise actions, behaviours and communication; and third, at the institutional level, property rights, laws and regulation contracts and other formal rules highly codify and regularise information flows. Fountain sustains that interactions among these three levels suggest that when information flows change at one level, the other two levels typically are affected to some extent. 


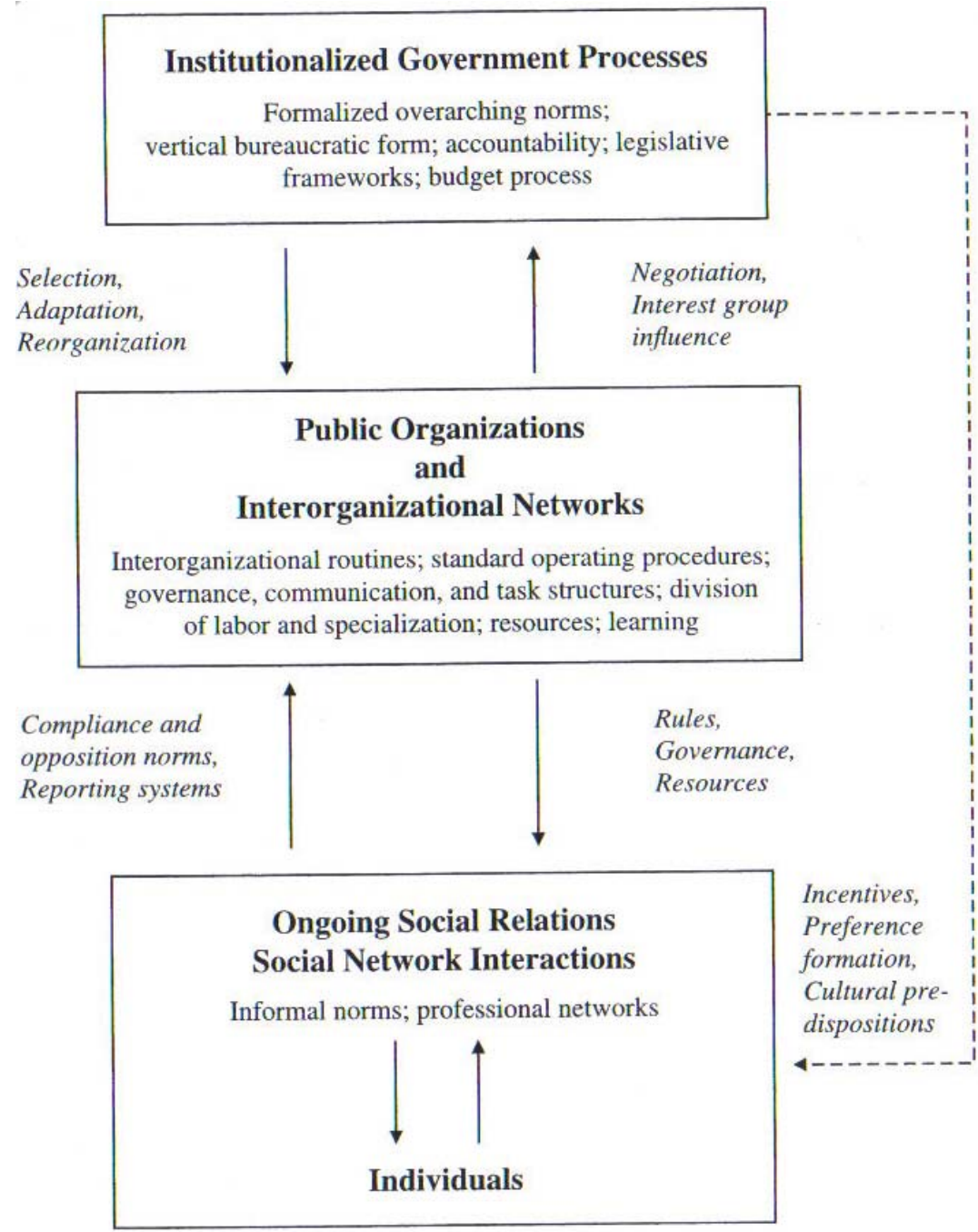

Figure 4.2

A multi-level integrated information system (MIIS).

Source: Fountain 2007

On one hand, social networks affect the flow and quality of information because much information is subtle and difficult to verify so actors would rather rely on people they know; individuals develop trust by repeated interaction and choose with whom to communicate and share knowledge (Fountain 2007). On the other hand, routinisation of information is, in part, what is meant by organisation, as individuals and smaller groups are constraint by these processes. Furthermore, there is a propensity of new information to flow through weak, rather than strong, ties between individuals. In our case, these are ties for example between 
individuals belonging to large, cross-agency networks across organisations (Fountain, 2007).

We hold the hypothesis that although radical transformations at the institutional/formal level of public organisations have not been observed, the new windows of interaction and the resulting citizens' aggregate information affect the dynamics (informal structure) of the administrations at the individual level of ongoing social relations and at some extent, at the organisational and inter-organisational level, through weak ties between individuals.

It also holds that citizens' related information travels to some extent throughout the administrations through informal channels - those not defined by organograms, institutional hierarchies and established rules - and, simultaneously, strengthens the informal organisational dynamics. This type of emergent networks, far from being the norm - as what we perhaps see is the coexistence more or less problematic and subject to tensions, of different organisational models (Aibar, Urgell and Welp 2007) - is perhaps where we would find more substantial transformations with the use of ICTs in government.

\section{III) Effects on Service Delivery}

This paper intends to build a theoretical and analytical framework to ultimately find out whether service delivery is affected by the emergence of the new technology-based windows of interactions - the hypothesis is that the organisational dynamics is changed and it affects the how services are delivered.

It is worth stressing that by "service delivery" this we mean those fully delivered online, such as the payment of taxes and school enrolment or, those that have the relevant information and logistic procedures about the service placed online, such as making a doctor's appointment. In other words, the quality of the doctor's appointment is not be analysed, but only the access to the information about the service and the interaction features related to it - is the information about citizen' behaviour and preferences with regards to making an appointment taken into consideration inside the administration and what are the effects on the restructuring of the organisation? And how are the effects on the offer of this online service? 


\section{Future Research}

Research on the subject may be benefited by thicker qualitative methods, such as ethnography, with a focus on one particular case, but we believe that a mixed-method approach might address the questions raised in this paper in a more effective and significant way. We propose a comparative study, between at least 3 regional/local governments have similar levels of political and financial autonomy and offer similar services, as they, by representing three models of political administration, public sector culture, and economic and e-government development, would enrich the comparison and analysis. On the other hand, e-government literature shows that governments face similar problems when implementing e-government projects, regardless of their inherent differences; the use of case studies increases the representativeness of the study.

Furthermore, within the context of comparative case studies, we suggest that a combination of semistructured interviews, documentation analysis, questionnaires, network analysis, and statistical analysis might prove useful to analyse the flows of information between citizens and governments and their effects in the administration and service delivery. Some steps that might help in the building of future research:

Situating Each Case Study: Through a review of specific literature about each government and region, an analysis of key economic, social, and "digital" variables, and extensive websites analysis (focusing on government-citizen interaction channels), we could understand both the general social context each administration is inserted into, and their specific state of development of technologybased channels of interaction between governments and citizens.

Snapshot of the Organisational Structure and Dynamics: Through documentation analysis (organograms, documents, job descriptions and functions), questionnaires and semi-structured interviews with key actors of the agencies in charge of the portals and call centres as well as of the departments involved in the research, we could investigate how aggregated information about citizens' preferences and online behaviour is produced and analysed and how/if it flows throughout the administration, and, on the other hand, how service delivery information is organised, at both the institutional/"formal" level and at the dynamic/"informal" level (network analysis).

Changes Along Time: Because of the difficulties in objectively isolate the specific relationship of 
new ICT-based channels of communication and oraganisational change from the effects of other ICT-related variables, we suggest a qualitative longitudinal analysis in order to understand changes in informal dynamics and organisational structure (analysis of written history, oral history, as well as the perceptions of the employees who have been working for a long time as public servants will be used as proxies for change).

Effects on Service Delivery: An analysis of the evolution of service delivery and of transformations in the structure and dynamics of the administrations might be done trough a I) qualitative evaluation of this evolution, always with respect to the information gathered about citizens' preferences and behaviour, and ii) quantitative data collection indicating improvement in service delivery (such as delivery time, use of paper, user's take up, time to wait in line, number of documents required from the citizen, etc).

We finally note that this is a first approximation of a theoretical and analytical framework to tackle the issue of the effects of feedback mechanisms and the vast amount of information about citizens' online behaviour and generation of content on the organisation of public administrations, and ultimately service delivery. Before applying this approach into practice, further work should be done, particularly on the methodology.

\section{References}

Aibar, E., Urgell, F., Welp, Y.: E-Governança i Atenció Ciutadana: La Generalitat De Catalunya En El Context Internacional. (2007)

Aibar, E., Urgell, F., Welp, Y.: De los Portales Publicos a la Administracin-Red? Un Estudio de Caso Sobre e-Governance. Coneixement i Societat, N7 (1) (2005)

Bhatnagar, S.: Access to Information: E-Government. In: Hodess, Inowlocki, Wolfe (eds.) Global Corruption Report. Profile Books Ltd. London (2003)

Bijker, W.: Of Bicycles, Bakelites, and Bulbs. Toward a Theory of Sociotechnical Change. MIT Press. Cambridge M.A. (1995)

Blakemore, M.: Customer-centric, citizen centric. Should Government learn directly from business? ccEgov Think Paper (2006) 
Borins, S. et al: Digital State at the Leading Edge. University of Toronto Press. Toronto (2007)

Castells, M.: The Internet Galaxy Reflections on the Internet, Business, and Society. Oxford University Press. Oxford, New York (2001)

Castells, M.: La Era de la Información (trilogy). Alianza. Madrid (1996-2000)

Chadwick, A.: Internet politics : States, citizens, and new communication technologies. Oxford University Press, New York ; Oxford (2006)

Dawes, S., Gregg,V., Agouris, P.: Digital Government Research: Investigations at the Crossroads of Social and Information Science. Social Science Computer Review 22(1): 5-10 (2004)

Dunleavy, P., Margetts, H.: The Advent of Digital Government: Public Bureaucracies and the State in the Internet Age. Paper for the Annual Conference of American Political Science Association. Washington D.C. (2000)

Dunleavy, P., Margetts, H., Bastow, S. and Tinkler, J.: Digital Era Governance: IT Corporations, the State and e-Government. Oxford University Press. Oxford (2006)

Fountain, J.: Challenges to Organizational Change: Multi-level Integrated Information Structures (MIIS). In: Lazer, D., Mayer-Schoenberger, V. (eds.): Governance and Information Technology: From Electronic Government to Information Government. MIT Press. Cambridge, MA (2007)

Fountain, J.: Central Issues in the Political Development of the Virtual State. In: Castells, M., Cardoso, G. (eds.): The Network Society: From Knowledge to Policy. Brookings Institution Press. Washington D.C. (2006)

Fountain, J.: Building the Virtual State: Information Technology and Institutional Change. Brookings Institution Press. Washington DC (2001)

Hague, B., Loader, B D.: Digital Democracy: Discourse and Decision Making in the Information Age. Routledge. London (1999)

Heeks, R., Bailur, S..: Analysing eGovernment Research: Perspectives, Philosophies, Theories, Methods and Practice. iGovernment Working Paper Series, N. 16. Development Informatics Group. University of Manchester (2006)

Heintze,T., and Bretschneider, S.: Information Technology and Restructuring in Public Organizations: Does Adoption of Information Technology Affect Organizational Structures, Communications, and Decision Making? Journal of Public Administration Research and Theory, Vol. 10, No. 4: 801-830 (2000)

Latour, B.: Aramis, or the love of technology. Harvard University Press. Cambridge Mass. (1996)

Mayer-Schönberger, V., \& Lazer, D.: Governance and information technology : From electronic government to information government. MIT Press, Cambridge, Mass. ; London (2007) 
Mayntz, R.:El Estado y La Sociedad Civil en la Gobernanza Moderna. Revista del CLAD Reforma y Democracia, vol. 21, October (2001)

Mason, J.: Qualitative Researching. Sage Publications. London (1996)

Marshall, M.: Sampling for Qualitative Research. Familiy Practice, Vol. 13, No. 6 (1996)

Milward, H.B. and Provan, K. G.: Managing the Hollow State: Collaboration and Contracting. Public Management Review, Vol. 5 (2003) 1-18

O'Callagham, R.: Technological Innovation in Organisations and Their Ecosystems. In: Dutton, W. H. et al (eds.): Transforming Enterprise: The Economic and Social Implications of Information Technology. The MIT Press. Cambridge M.A. (2004)

Orlikowski, W.: Using Technology and Constituting Structures: A Practice Lens for Studying Technology in Organizations. Organization Science, vol.11, No.4, 404:428 (2000)

Pinsonneault, A., Kraemer, K.: The Impact of Information Technology on Middle Managers. MIS Quarterly, 17 (3), 271-292 (1993)

Powell, W. W.: Neither Market nor Hierarchy: Network Forms of Organization. Research in Organizational Behavior, Vol. 12 (1990) 295-336.

Osborne, D., Gaebler. T.: Reinventing Government: How the Entrepreneurial Spirit Is Transforming the Public Sector. Addison-Wesley. Reading, MA (1992)

Schellong, A.: Crossing the Boundary - Why Putting the e in Government is the Easy Part. PNG Working paper N. PNG07-002. John F. Kennedy-Harvard School of Government (2007)

United Nations.: Global e-Government Readiness Report 2005: From e-Government to e- Inclusion. (2005)

Stewart, J., Walsh, K.: Change in the management of public services. Public Administration, Vol. 70 pp.499-518 (1992)

Van Dijk, J.: The Network Society: Social aspects of new media. Sage, London (1999)

Wall-Smith, M.: The Network Society: A Shift in Cognitive Ecologies? First Monday, 7 (2002)

UNPAN: The Stages of e-Government Development. http://www.unpan.org/e- government/stages.htm

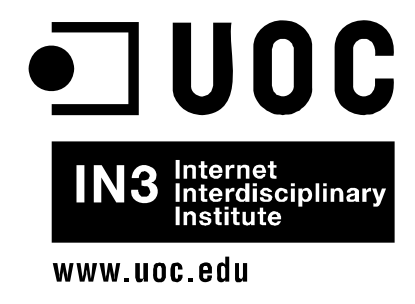

